\title{
Evaluation of Corrosion Product Activity in a Typical PWR with Extended Cycles and Flow Rate Perturbations
}

\author{
Rubina Nasir ${ }^{1}$, Sikander M. Mirza², Nasir M. Mirza ${ }^{2 *}$ \\ ${ }^{1}$ Department of Physics, Air University, Islamabad, Pakistan \\ ${ }^{2}$ Department of Physics \& Applied Mathematics, Pakistan Institute of Engineering \& Applied Sciences, \\ Islamabad, Pakistan \\ Email: ${ }^{\star}$ mmm@pieas.edu.pk, ${ }^{\star}$ nasirmm@yahoo.com
}

How to cite this paper: Nasir, R., Mirza, S.M. and Mirza, N.M. (2017) Evaluation of Corrosion Product Activity in a Typical PWR with Extended Cycles and Flow Rate Perturbations. World Journal of Nuclear Science and Technology, 7, 24-34. http://dx.doi.org/10.4236/wjnst.2017.71003

Received: November 1, 2016 Accepted: December 31, 2016 Published: January 3, 2017

Copyright ( 92017 by authors and Scientific Research Publishing Inc. This work is licensed under the Creative Commons Attribution International License (CC BY 4.0). http://creativecommons.org/licenses/by/4.0/

\begin{abstract}
Effect of flow rate perturbations has been studied using the modified computer program CPAIR-P for time dependent corrosion rates in Pressurized Water Reactors (PWRs) having extended cycles. In these simulations, a decrease in the corresponding saturation values of corrosion product activity (CPA) is observed for higher $\mathrm{pH}$ values. Comparison of CPA's behavior has been done for constant flow-rate case as well as for transients with elevated ${ }^{10} \mathrm{~B}$ levels $(\sim 40 \%)$ in dissolved boric acid in coolant in two operating cycles. When the flow rate is decreased in the first cycle, the saturation value of CPA attains new higher values. Also, in the second operating cycle, the saturation values are about $12 \%$ higher when compared with the values in the first cycle.
\end{abstract}

\section{Keywords}

PWRs, Corrosion Products, Enriched Boric Acid, Extended Cycles, Flow Rate Perturbations

\section{Introduction}

Recent Pressurized Water Reactors (PWRs) are aiming at better performance of nuclear plants by increasing the fuel cycle length as high burn-up leads to better utilization of fuel as well as generation of higher revenues [1]. Recent studies indicate that enriched boric acid (EBA) decreases the requirement of high concentrations and the high value of $\mathrm{pH}(\sim 7.4)$ can be done with $2.2 \mathrm{ppm}$ of lithium. It also does not introduce the corrosion cracking problems in Pressurized Water Reactors (PWRs) [2] [3] [4]. This can improve the discharged burnup from average value of $33 \mathrm{MWd} / \mathrm{kgU}$ to $40-50 \mathrm{MWd} / \mathrm{kgU}$. 
However, extended cycles put higher safety limits on fuel integrity for longer fuel residence time in core and corrosion induced cracking is one of the major reasons for material failure in PWRs [5]. When the corrosion elements come from the magnetite $\left(\mathrm{Fe}_{3} \mathrm{O}_{4}\right)$, the $\mathrm{pH}$ levels of 7.3 - 7.4 are needed instead of 6.9. Also, high values of temperature in the system can cause highly corrosive coolant and decomposition of water further increases its corrosion [1] [4]. The corrosion rate in PWRs increases with the effective full power days [6]. The observed increase involves many factors including phase transformations that occur due to aging and decomposition of stainless steel [7] etc. The corrosion elements get activated by circulation in reactor core. Large value of corrosion product activity (CPA) in the primary loop does become a problem to the reactor maintenance [6] [8].

In PWRs, the CPA mainly comes from short-lived ${ }^{56} \mathrm{Mn}$ and ${ }^{24} \mathrm{Na}$. However; iron, molybdenum and cobalt make almost all of the activity after shutdown of reactor. Table 1 shows some properties of these isotopes [9]. Primary coolant in PWRs maintains very high dose due to the CPA even after the reactor shutdown. Also, the end of cycle coolant activity can further increase due to any transient condition during reactor operation [8] [9]. The soluble forms of ${ }^{60} \mathrm{Co},{ }^{58} \mathrm{Co}$ and ${ }^{54} \mathrm{Mn}$ show dependence on flow rate, $\mathrm{pH}$ values and boron [10] [11].

Several studies have been carried out on coolant activation in nuclear reactors with focus on the flow rate \& power transients. Reactor transient studies indicate that reactivity as well as flow rate perturbations result in neutron flux peaking [12] For PWRs, Venz and Weidmann showed that the coolant chemistry is important for extended fuel cycles. Coolant Activity at Beznau nuclear power plant was reduced when the $\mathrm{pH}$ levels in the coolant were raised to 7.4 [13].

Table 1. Activation products and their reaction properties.

\begin{tabular}{|c|c|c|c|}
\hline Corrosion products & Reaction and neutron energy* & Activation cross-section and half-life & $\gamma$-ray energy $\mathrm{MeV}(\text { Intensity } \%)^{*}$ \\
\hline${ }^{24} \mathrm{Na}$ & $\begin{array}{l}{ }^{27} \mathrm{Al}(n, \alpha)^{24} \mathrm{Na} \\
\left(E_{n}>11.6 \mathrm{MeV}\right) \\
{ }^{23} \mathrm{Na}(n, \gamma)^{24} \mathrm{Na} \\
\left(E_{n} \text { is thermal }\right)\end{array}$ & $\begin{array}{c}6 \times 10^{-8} \text { barn } \\
\left(5.3989 \times 10^{4} \mathrm{~s}\right) \\
0.53 \times 10^{-4} \text { barn } \\
\left(5.3989 \times 10^{4} \mathrm{~s}\right)\end{array}$ & $\begin{array}{l}1.368(99.994) \\
2.754(99.855)\end{array}$ \\
\hline${ }^{56} \mathrm{Mn}$ & $\begin{array}{c}{ }^{55} \mathrm{Mn}(n, \gamma)^{56} \mathrm{Mn} \\
\left(E_{n} \text { is thermal) }\right.\end{array}$ & $\begin{array}{c}13.4 \text { barn } \\
\left(9.2808 \times 10^{3} \mathrm{~s}\right)\end{array}$ & $\begin{array}{c}0.8467(98.85) \\
1.8107(26.9) \\
2.1131(14.2) \\
2.5231(1.02)\end{array}$ \\
\hline${ }^{59} \mathrm{Fe}$ & $\begin{array}{l}{ }^{58} \mathrm{Fe}(n, \gamma){ }^{59} \mathrm{Fe} \\
\left(E_{n} \text { is thermal }\right)\end{array}$ & $\begin{array}{c}0.9 \times 10^{-4} \text { barn } \\
\left(1.6018 \times 10^{5} \mathrm{~s}\right)\end{array}$ & $\begin{array}{l}0.1426(1.02) \\
0.1923(3.08) \\
1.0992(56.5) \\
1.2916(43.2)\end{array}$ \\
\hline${ }^{60} \mathrm{Co}$ & ${ }^{59} \mathrm{Co}(n, \gamma){ }^{60} \mathrm{Co}$ & $\begin{array}{c}2 \times 10^{-3} \text { barn } \\
\left(1.6638 \times 10^{8} \mathrm{~s}\right)\end{array}$ & $\begin{array}{l}1.1732(99.85) \\
1.3325(99.98)\end{array}$ \\
\hline${ }^{99} \mathrm{Mo}$ & $\begin{array}{c}{ }^{98} \mathrm{Mo}(n, \gamma){ }^{99} \mathrm{Mo} \\
E_{n}>3.1 \mathrm{MeV}\end{array}$ & $\begin{array}{c}0.45 \times 10^{-4} \text { barn } \\
\left(2.3751 \times 10^{5} \mathrm{~s}\right)\end{array}$ & $\begin{array}{c}0.1811(6.14) \\
0.3664(1.20) \\
0.7395(12.26) \\
0.7779(4.3)\end{array}$ \\
\hline
\end{tabular}

${ }^{\star}$ Interactive chart of Radionuclides NuDat 2.6, NNDC Databases, Brookhaven National Laboratory (http://www.nndc.bnl.gov/nudat2/chartNuc.jsp). 
The time dependent CPA in primary loops of PWRs was carried out for flow rate and power changes using constant corrosion rate models [14]. Program CPAIR was written in FORTRAN-77 and it was developed for assessment of primary coolant activity due to several corrosion products in light water reactors. The program was modified as CPAIR-P for effects of fast as well as slow transients on CPA in coolant. Recently the time dependent corrosion product activity calculations were performed after modifying CPAIR-P code for PWRs with long-term operating cycles using coolant chemistry parameters [11].

In this work we focus on time dependent behavior for CPA in primary circuits of PWRs with extended cycles having flow rate transients and necessary changes were made in CPAIR-P code for nonlinear corrosion rates and $\mathrm{pH}$ values. Then for two extended operating cycles the CPA is estimated in the presence of both nonlinear corrosion rates and changes in $\mathrm{pH}$ values under flow rate transients.

\section{Coolant Chemistry for Extended Cycles}

Numerous studies have revealed that operating cycle in light water reactors is extendable to burnup value of $45 \mathrm{MWd} / \mathrm{kgU}$ in PWRs. The operating cycles of 18 to 24 month duration show an increase in the capacity factor from $3 \%$ to $7 \%$ [2] [3] [4]. At the beginning of the cycle for a PWR, $1200 \mathrm{ppm}$ of boron is used in a 12 month cycle. Also initially the $\mathrm{pH}$ value of 6.9 is obtained with the help of lithium levels. Initial boron concentration must be higher ( 1500 to $1900 \mathrm{ppm})$ for long operating cycles. This in turns translates into much higher $\mathrm{pH}$ values in the coolant. The Enriched Boric Acid reduces the required amount of chemical shim. Therefore, high $\mathrm{pH}$ value (7.4) is used in the reactor along with $2 \mathrm{ppm}$ of lithium to keep long operating cycles [4].

The long operating cycles employ this scheme in which the coolant has higher $\mathrm{pH}$ in start of the cycle along with high values of boron and lithium concentrations. After that, steadily $\mathrm{pH}$ value is elevated to 7.4 and then kept constant till the end of cycle. Various scenarios for $\mathrm{pH}$ changes in a typical PWR versus effective full power days are shown as Figure 1 [1]. The $\mathrm{pH}$ variations for long cycles are shown as Figure 1. In the first case, Natural Boric Acid (NBA) is used with lithium and $\mathrm{pH}$ as $2.2 \mathrm{ppm}$ and 6.9 respectively.

\section{Mathematical Model}

Using deterministic simulation technique a mathematical model was developed and implemented into a computer code along with a suitable numerical integration method. The time derivative of active concentration is given by [14]:

$$
\frac{d n_{w}}{d t}=\sigma \varphi_{\varepsilon} N_{\omega}-\left\{\sum_{j} \frac{\varepsilon_{j} Q_{j}}{V_{w}}+\sum_{k} \frac{l_{k}}{V_{w}}+\lambda\right\} n_{w}+\frac{K_{p}}{V_{w}} n_{p}+\frac{K_{c}}{V_{w}} n_{c}
$$

where, $\sigma$ is the group constant. The effective one-group flux is given by $\phi_{\varepsilon}$ $\left(\# / \mathrm{cm}^{2} \cdot \mathrm{s}\right)$ and $N_{w}\left(\# / \mathrm{cm}^{3}\right)$ represents the concentration of target nuclide in water. The $N_{w}, N_{p}$ and $N_{c}$ have meanings of target concentrations in water, piping and core, in atoms $/ \mathrm{cm}^{3}$. The values of concentrations of the activation 
products in primary coolant, piping and core are given as $n_{w}, n_{p}$ and $n_{c}$ respectively, in \#/ $\mathrm{cm}^{3}$. The sum over $j$ for $\varepsilon_{j} Q_{j}$ is given by:

$$
\sum_{j} \varepsilon_{j} Q_{j}=\varepsilon_{I} Q_{I}+\varepsilon_{p} Q_{p}+\varepsilon_{c} Q_{c}+\varepsilon_{F} Q_{F}
$$

where, $\varepsilon_{I} Q_{I}, \varepsilon_{p} Q_{p}, \varepsilon_{c} Q_{c}$ and $\varepsilon_{F} Q_{F}$ represent values of removal rates for ion exchanger, deposition on pipes, core surface depositions and filter based removals, respectively. The primary coolant leakage rate from the $k$ th leak is given by $l_{k}$ and removal rates from piping scale and from core surface are given by $K_{p}$ and $K_{c}$ respectively in $\# / \mathrm{cm}^{2} \cdot$ s. Table 1 gives summary of decay data for various isotope of interest. In this work, experimental values of the removal rates from the published PWR data were used [10]. Some of the values are shown in Table 2 [10] [11].

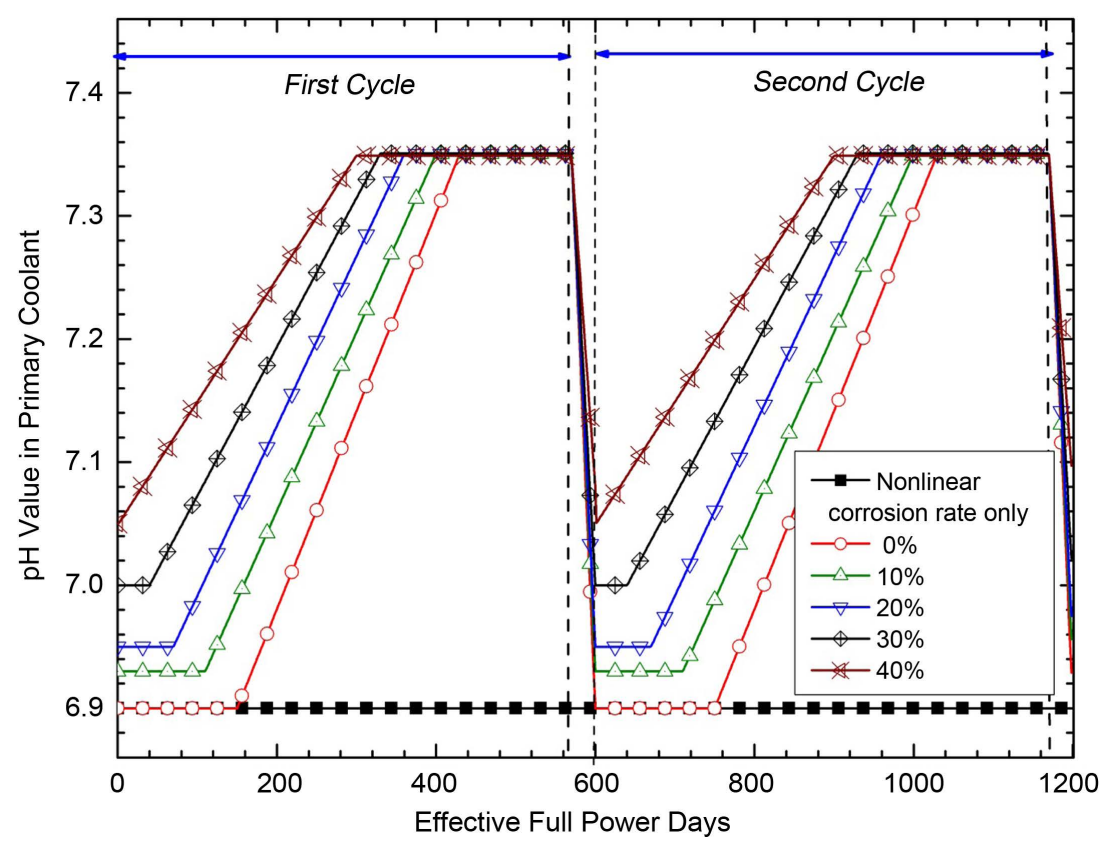

Figure 1. The pH-value in the primary coolant for two cycles as a function of effective full power days (EFPDs) for various indicated values of $10 \mathrm{~B}$ in boric acid.

Table 2. Experimental values of exchange rates in a typical PWR.

\begin{tabular}{cc}
\hline Rate type & Value \\
\hline Deposition on core $\left(\varepsilon_{c} Q_{c}\right)$ & $80.0 \mathrm{~cm}^{3}$ per second \\
Deposition on piping $\left(\varepsilon_{p} Q_{P}\right)$ & $13.7 \mathrm{~cm}^{3}$ per second \\
Ion-exchanger removal $\left(\varepsilon_{I} Q_{I}\right)$ & 500 to $781 \mathrm{~cm}^{3}$ per second \\
Re-solution ratio for core $\left(K_{c}\right)$ & $40.0 \mathrm{~cm}^{3}$ per second \\
Re-solution ratio for piping $\left(K_{p}\right)$ & $6.9 \mathrm{~cm}^{3}$ per second \\
Volume of primary coolant $\left(V_{W}\right)$ & $1.37 \times 10^{7} \mathrm{~cm}^{3}$ \\
Volume of scale on core $\left(V_{c}\right)$ & $9.08 \times 10^{6} \mathrm{~cm}^{3}$ \\
Volume of scale on piping $\left(V_{P}\right)$ & $1.37 \times 10^{6} \mathrm{~cm}^{3}$ \\
Total corrosion surface $(S)$ & $1.01 \times 10^{8} \mathrm{~cm}^{2}$ \\
Average corrosion rate $\left(C_{o}\right)$ & $2.4 \times 10^{-13} \mathrm{gm} \mathrm{per} \mathrm{cm}^{2}$ per s \\
\hline
\end{tabular}


The temporal variation of dissolved boron in primary coolant are given by a parameter $h(t)$ :

$$
h(t)=\left\{\begin{array}{l}
a_{0} ; a_{0} \leq 1, \quad t_{\min }<t<t_{1} \\
1+\psi\left\{p h(\xi, t)-p h\left(\xi, t_{0}\right)\right\} ; \quad t_{1}<t<t_{2} \\
b_{0} ; b_{0} \leq 1, \quad t_{2}<t<t_{\max }
\end{array}\right.
$$

here, $\psi$ represents the slope estimated from the power plant operation data; $\operatorname{ph}(\xi, t)$ is boric acid concentration $(\xi)$ and time dependent $\mathrm{pH}$-value; $a_{0}$ and $b_{0}$ are fractions in the initial and final phases of operation cycle. The residence time of primary coolant in core is represented by $T_{c}$ while the time taken for circulating once in primary circuit is given by $T_{L}$. The temporal variation of concentration of target nuclide can be given as

$$
\begin{gathered}
\frac{d N_{w}}{d t}=-\left\{\sum_{j} \frac{\varepsilon_{j} Q_{j}}{V_{w}}+\sum_{k} \frac{l_{k}}{V_{w}}+\sigma \varphi_{\varepsilon}\right\} N_{w}+\frac{K_{p}}{V_{w}} N_{p}+\frac{K_{c}}{V_{w}} N_{c}+S_{w} \\
S_{w}=\frac{C(t) S}{V_{w}} \frac{N_{0}}{A} f_{n} f_{s}
\end{gathered}
$$

where, $N_{p}$ and $N_{c}$ represent the target nuclide concentration on the piping and on the core respectively and $S_{w}$ represents the corrosion production rate.

The removal rates by ion-exchanger, core deposition and leakage are function of primary coolant flow rate. The corresponding rate of the core scale activity is given by following model:

$$
\frac{d n_{c}}{d t}=\sigma \phi_{0} N_{c}+\frac{\varepsilon_{c} Q_{c}}{V_{c}} n_{w}-\left\{\frac{K_{c}}{V_{c}}+\lambda\right\} n_{c}
$$

where, the volume of the scale on the reactor core surface is given by $V_{c}\left(\mathrm{~cm}^{3}\right)$. The $\phi_{0}$ is core averaged thermal neutron flux (neutrons $/ \mathrm{cm}^{2} \cdot \mathrm{s}$ ). The temporal variation of concentration of target nuclide on the core scale $\left(N_{c}\right)$ is:

$$
\frac{d N_{c}}{d t}=\frac{\varepsilon_{c} Q_{c}}{V_{c}} N_{w}-\left\{\frac{K_{c}}{V_{c}}+\sigma \phi_{0}\right\} N_{c}
$$

The governing equation for the rate of change of active material on the piping scaling $\left(n_{p}\right)$ is given by the following expression:

$$
\frac{d n_{p}}{d t}=\frac{\varepsilon_{p} Q_{p}}{V_{p}} n_{w}-\left\{\frac{K_{p}}{V_{p}}+\lambda\right\} n_{p}
$$

where, the scale volume on the piping is $V_{p}\left(\mathrm{~cm}^{3}\right)$. Then, the temporal variation of target nuclide on piping walls $\left(N_{p}\right)$ is

$$
\frac{d N_{p}}{d t}=\frac{\varepsilon_{p} Q_{p}}{V_{p}} N_{w}-\frac{K_{p}}{V_{p}} N_{p}
$$

Using the above system of Equations (1)-(9), the CPAIR-P computer code [14] has been upgraded in the present study to incorporate temporal variations in corrosion rates along with the $\mathrm{pH}$ values and chemical shim.

The upgraded version of CPAIR-P code now simulates the CPA incorporating time dependent corrosion rates and primary coolant chemistry. This program 
uses the core design parameters to estimate the group constants (Table 3). For this purpose, the LEOPARD [15] code is employed as subroutine in CPAIR-P/PH program. The LEOPARD is a unit cell based computer program using 54 fast \& 172 thermal energy groups used for criticality calculations and group constant generations. Subsequently ODMUG program by Thomas and Edlund developed in 1980 was used for computation of detailed spatial group fluxes [16].

\section{Results and Discussion}

In this work, computer simulations were done for a typical PWR with a clean system having none impurities [17]. The fractional exchange and re-solution rates were taken from the experimental data for the typical PWR. These experimental values of deposition and re-solution rates are given in Table 2. Also, the values of plant specific data are given as Table 3 [10] [11]. The corrosion prone plant surface area of $10^{8} \mathrm{~cm}^{2}$ is in contact with the primary coolant. Also, in recent work [8] it was shown that corrosion rate approaches an equilibrium value of $2.4 \times 10^{-13} \mathrm{~g} / \mathrm{cm}^{2}$-s. Such a PWR has coolant volume equal to $1.3 \times 10^{7} \mathrm{~cm}^{3}$. In this work we have used the same for the simulations. Figure 2 gives algorithmic details of this program in the form of schematic flow chart.

In first part, the equilibrium value of removal rate of CPA by the ion-exchanger $\left(\varepsilon_{I} Q_{I}\right)$ was found taking a constant value of corrosion rate and the details of methodology can be found in the Reference $14 \& 17$ respectively. These simulations indicate that the final value for CPA becomes constant when $\varepsilon_{I} Q_{I}$ becomes higher than $400 \mathrm{~cm}^{3} / \mathrm{s}$. Consequently, the value of $600 \mathrm{~cm}^{3}$ per second was used for removal rate in this work. Behavior of dominant corrosion

Table 3. Typical design specifications of a PWR.

\begin{tabular}{cc}
\hline Parameter & Value \\
\hline Specific power $(\mathrm{MW}(\mathrm{th}) / \mathrm{kg} \mathrm{U}$ & 33 \\
Power density $\left(\mathrm{MW}(\mathrm{th}) / \mathrm{m}^{3}\right)$ & 102 \\
Core height $(\mathrm{m})$ & 4.17 \\
Core diameter $(\mathrm{m})$ & 3.37 \\
Assemblies & 194 \\
Rods per assembly & 264 \\
Fuel type & $\mathrm{UO} 2$ \\
Clad type & Zircoloy \\
Lattice pitch $(\mathrm{mm})$ & 12.6 \\
Fuel rod outer diameter $(\mathrm{mm})$ & 9.5 \\
Average enrichment $\left({ }^{\mathrm{w}} \%\right)$ & 3.0 \\
Flow rate $(\mathrm{Mg} / \mathrm{s})$ & 18.3 \\
Linear heat rate $\left(\mathrm{kW} / \mathrm{m}^{2}\right)$ & 17.5 \\
Coolant pressure $(\mathrm{MPa})$ & 15.5 \\
Inlet coolant temperature $\left({ }^{\circ} \mathrm{C}\right)$ & 293 \\
Outlet coolant temperature $\left({ }^{\circ} \mathrm{C}\right)$ & 329 \\
\hline
\end{tabular}




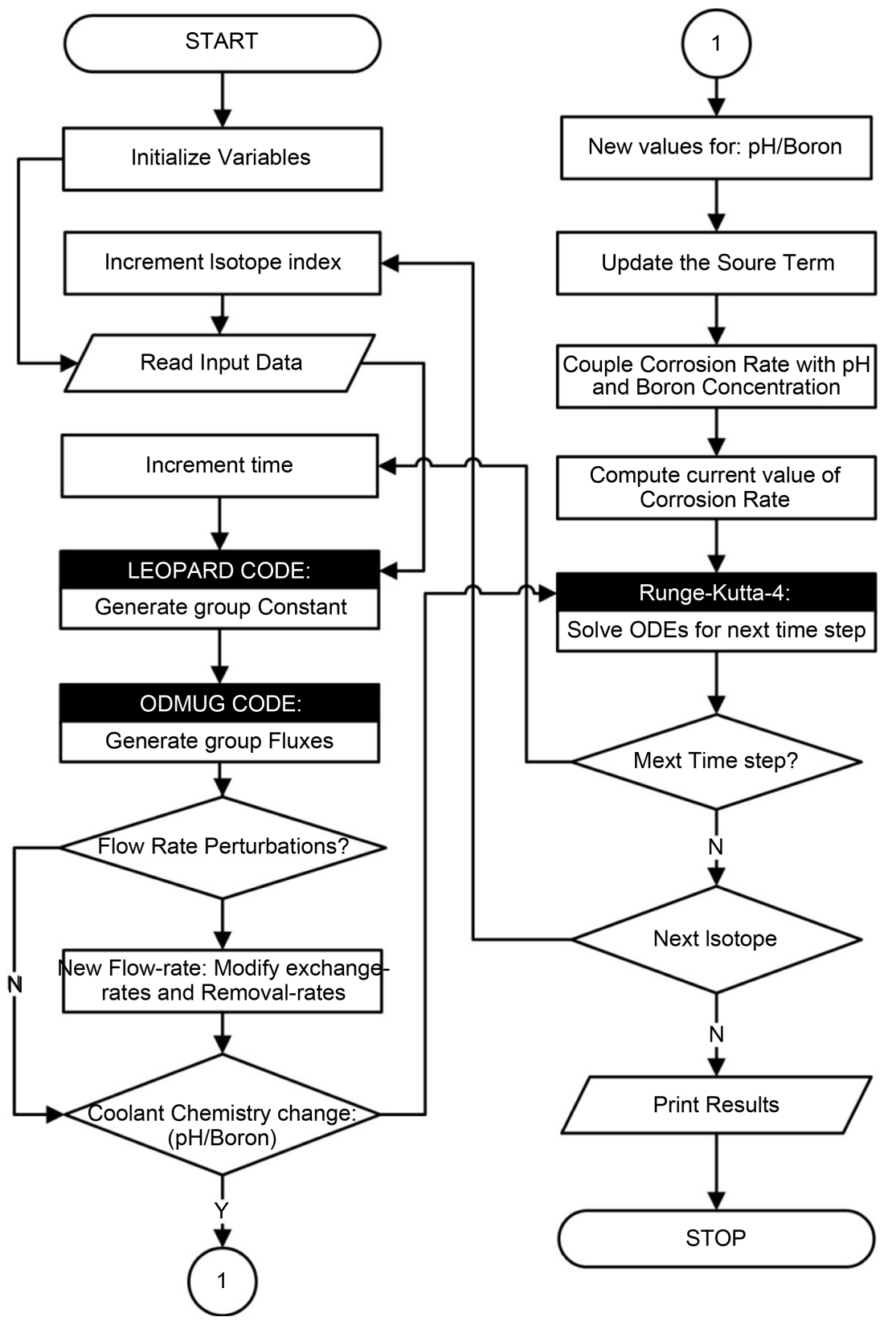

Figure 2. Logical flow chart of the computer modified program CPAIR-P/PH.

isotopes $\left({ }^{56} \mathrm{Mn}\right.$, and $\left.{ }^{60} \mathrm{Co}\right)$ was observed and we saw that when reactor is operating the main contribution comes from ${ }^{56} \mathrm{Mn}$ and after the shutdown the cobalt isotopes dominate the activity.

\subsection{Time Dependent pH Value}

Typical behavior of the $\mathrm{pH}$-values for two cycles as a function of time is shown as Figure 1. Here, different curves indicate different levels of ${ }^{10} \mathrm{~B}$ in mixed in the chemical shim. When mixed B-10 is high the $\mathrm{pH}$-value becomes also high in the system. Figure shows that the $\mathrm{pH}$ level gradually increases from lower to higher values and it saturates to about 7.35 in both first and second cycle. Increase in $\mathrm{pH}$ value lowers the solubility of corrosion products in the coolant. Also high $\mathrm{pH}$ 
results in a positive temperature coefficient of solubility and this reduces the transport of corrosion products. Also, any increase in the operation length will affect the generation of corrosion product. In this work, we have assumed a constant corrosion rate during the steady state operation.

\subsection{Nonlinear Changes in Corrosion and pH Effects}

PWRs have in general nonlinear changes in the corrosion rate during their operation. This is in addition to the coolant chemistry effects. The following mathematical model is used for the first cycle:

$$
C(t)=\left\{\begin{array}{l}
0, \quad 0<t<a \\
h(t) C_{s}\{1-\exp (-m(t-a))\}, \quad a \leq t \leq b \\
h(t) f_{c s} C_{s}, \quad b<t \leq c
\end{array}\right.
$$

The variable $m$ represents slope having a constant value in the time interval $a \leq t \leq b$. The variable $C_{s}$ represents the optimum value of rate attained for $t>$ $b$.

Similarly for the second cycle, the initial corrosion rate is non-zero because of a residual value from the first cycle which is enhanced by an increase in corrosion rate along with a opposing decrease due to effects of the $\mathrm{pH}$-value. It is mathematically modeled by the following expression:

$$
C(t)=\left\{\begin{array}{l}
h(t)\left[f_{c s} C_{s}+C_{s}\{1-\exp (-m(t-c))\}\right], \quad c \leq t \leq d \\
h(t) f_{c s}\left[C_{s}+f_{c s} C_{s}\right], \quad d \leq t \leq e
\end{array}\right.
$$

The values of 600, 1170 and 1200 days were used for $c, d$, and $e$ respectively. The activity was then determined from the modified program CPAIR-P for both cycles. These simulations were carried out for various boron concentration scenarios. When $h(t)=1$, the effect of $\mathrm{pH}$-value is nominal and saturation values are largest of all cases. During first cycle, saturation values for Co-60 are 0.24 $\mu \mathrm{Ci} / \mathrm{cm}^{3}$ (core region), $0.10 \mu \mathrm{Ci} / \mathrm{cm}^{3}$ (primary pipes) and $0.016 \mu \mathrm{Ci} / \mathrm{cm}^{3}$ (primary coolant).

\subsection{Flow Rate Perturbations}

When the cross-sectional area for flow changes and/or the primary pump speed gets reduced then the flow rate transient occurs in the reactor. As a result the fuel, moderator and coolant temperatures change and start affecting the neutron flux. This further modifies the production of activated corrosion products and their loss terms. In this work, we have introduced a flow rate perturbation taking PWR operating at full power and the activated products has reached to their saturation values. Here we have not allowed the reactor to scram during these simulations to study the consequences of these simulations. Using the modified CPAIR-P program, the corrosion product activity was estimated in the coolant, primary pipe scale and in the reactor core. Flow rate changes were assumed to be linear and were started at time, $t_{\text {in }}$ and remained effective for $t_{\max }-t_{\mathrm{in}}$ time period. Such a model is introduced by the parameter $g(t)$ : 


$$
g(t)= \begin{cases}1, & t<t_{\text {in }} \\ 1-\alpha\left(t_{\text {in }}-t\right), & t_{\text {in }} \leq t \leq t_{\max } \\ w_{f} / w_{0}, & t>t_{\max }\end{cases}
$$

Flow rate decrease has a slope of $\alpha$ and $t_{\text {in }}$ is the time of initiation of mass flow rate perturbation.

The mass flow rate perturbation is initiated at $t_{0}=300 \mathrm{~d}$ for several $\Delta w=w_{f}-w_{0}$ values. In time period of ten days the flow rate decreases from $w_{0}$ to $w_{f}$. The reactor remains at full power and it is not allowed to undergo a scram. Simulation results for first and second cycle are shown as Figure 3 for activity due to ${ }^{60} \mathrm{Co}$ for $40 \%{ }^{10} \mathrm{~B}$ in chemical shim. The results for the first cycle indicate that CPA approaches a higher final value. The new saturation value keeps on increasing when $\Delta w=w_{f}-w_{0}$ is increased. If the flow rate is allowed to change, $\Delta w$ is varied from 0 to $0.8 w_{0}$. Then, the new saturation activity in coolant increases from $0.011 \mu \mathrm{Ci} / \mathrm{cm}^{3}$ to $0.017 \mu \mathrm{Ci} / \mathrm{cm}^{3}$. When the ion-exchanger purification rate, $\varepsilon_{I} Q_{I}$, becomes low than these saturation value will increase further. Also, an increased deposition, re-solution and leakage can also get increased in these transients. Similarly, for the second cycle the simulations predict higher peak values in comparison with peak values in the first cycle (Figure 3 ). Also, the saturation values in the second operating cycle are about $14 \%$ higher as compared with the values in the first cycle. These results indicate that flow rate perturbations substantially affect the balance of CPA in PWRs and their effects propagate in next operating cycles.

\section{Conclusion}

The CPA under flow rate perturbations was investigated in primary loop of a

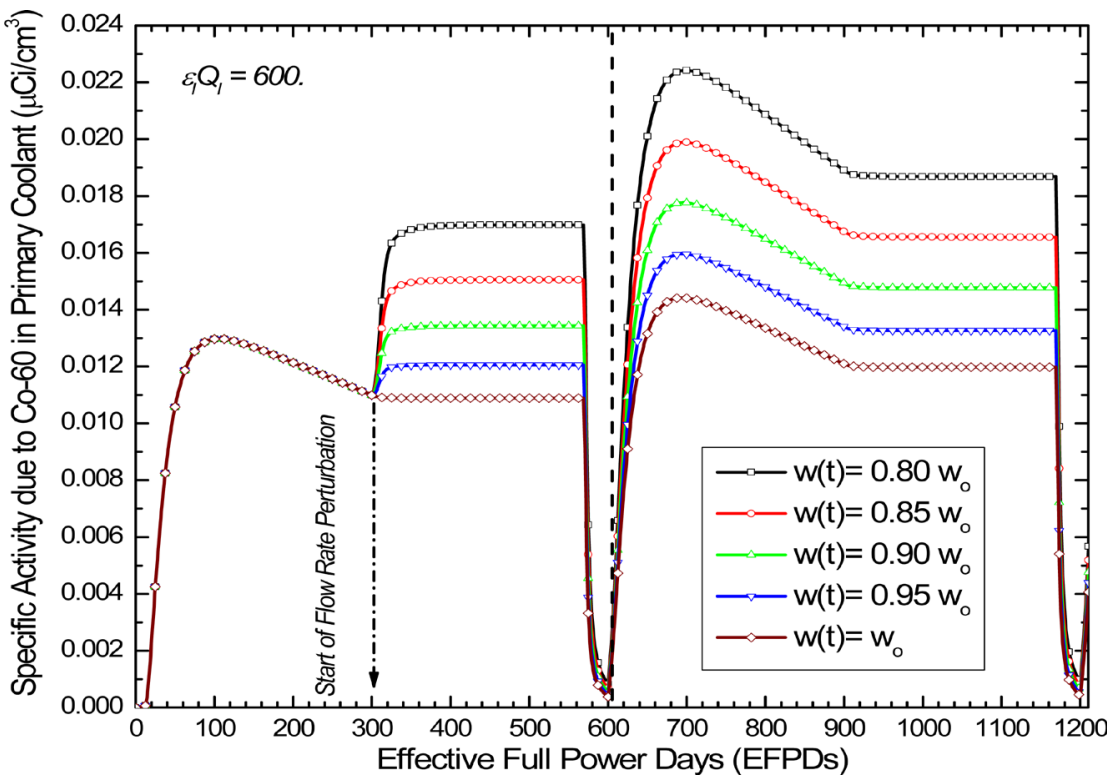

Figure 3. Comparison of specific activity due to $60 \mathrm{Co}$ in the primary coolant under flow rate perturbation having nonlinearly rising corrosion rate and $40 \% 10 \mathrm{~B}$ in dissolved boric acid. Flow rate perturbation is introduced at 300 day for $\Delta t=10$ days. 
typical PWR with long operating cycle. These cycles affect the primary coolant chemistry in terms of operational levels of boron and optimum $\mathrm{pH}$ values. These simulations indicate that for the normal reactor operation conditions the values of specific CPA approach equilibrium value fairly quickly. The $\mathrm{pH}$ values, removal rates and cycle length affect the saturation level of CPA in the system. The CPA levels have been compared for flow rate transients in the presence of higher levels of ${ }^{10} \mathrm{~B}$ in chemical shim. When the flow rate transient is applied, the saturation values of CPA go up. If the flow rate is allowed to change, $\Delta w$ is varied from 0 to $0.8 w_{0}$. Then, the new saturation level in the coolant increases from $0.011 \mu \mathrm{Ci} / \mathrm{cm}^{3}$ to $0.017 \mu \mathrm{Ci} / \mathrm{cm}^{3}$. The saturation values in the second operating cycle are about $12 \%$ higher when compared with values in the first cycle.

\section{References}

[1] Song, M.C. and Lee, K.J. (2003) The Evaluation of Radioactive Corrosion Product at PWR as Change of Primary Coolant Chemistry for Long-Term Fuel Cycle. Annals of Nuclear Energy, 30, 1231-1246. https://doi.org/10.1016/S0306-4549(03)00054-9

[2] EPRI Report (1995) Experience with Elevated pH at the Millstone Point 3 PWR. EPRI TR-105345.

[3] EPRI Report (1995) PWR Primary Water Chemistry Guidelines: Revision 3. EPRI TR-105714.

[4] KAERI Report (1995) Study on Chemical and Volume Control System Design Improvement of PWR to Use the Enriched Boric Acid. KAERI-RR-1591.

[5] Yamazaki, S., Lu, Z., Ito, Y., Takeda, Y. and Shoji, T. (2008) The Effect of Prior Deformation on Stress Corrosion Cracking Growth Rates of Alloy 600 Materials in a Simulated Pressurized Water Reactor Primary Water. Corrosion Science, 50, 835846. https://doi.org/10.1016/j.corsci.2007.07.012

[6] Varga, K., Hirchberg, G., Nemth, Z., Myburg, G., Schunk, J. and Tilky, P. (2001) Accumulation of Radioactive Corrosion Products on Steel Surfaces of VVER-Type Nuclear Reactors. II. 60Co. Journal of Nuclear Materials, 298, 231-238. https://doi.org/10.1016/S0022-3115(01)00658-4

[7] Park, C.-J. and Kwon, H.-S. (2002) Effects of Aging at $475^{\circ} \mathrm{C}$ on Corrosion Properties of Tungusten-Containing Duplex Stainless Steels. Corrosion Science, 44, 28172830. https://doi.org/10.1016/S0010-938X(02)00079-3

[8] Mirza, N.M., Rafique, M., Mirza, S.M. and Hyder, M. J. (2005) Simulation of Corrosion Product Activity for Nonlinearly Rising Corrosion on Inner Surfaces of Primary Coolant Pipes of a Typical PWR under Flow Rate Transients. Applied Radiation \& Isotopes, 62, 681-692. https://doi.org/10.1016/j.apradiso.2004.12.005

[9] NuDat-2.6 (2012) Interactive Chart of Radionuclides NuDat 2.6, NNDC Databases. Brookhaven National Laboratory, Upton. http://www.nndc.bnl.gov/nudat2/chartNuc.jsp

[10] Rafique, M., Mirza, N.M. and Mirza, S.M. (2005) Kinetic Study of Corrosion Product Activity in Primary Coolant Pipes of a Typical PWR under Flow Rate Transients and Linearly Increasing Corrosion Rates. Journal of Nuclear Materials, 346, 282292.

[11] Malik, J.I., Mirza, N.M. and Mirza, S.M. (2012) Time-Dependent Corrosion Product Activity in a Typical PWR Due to Changes in Coolant Chemistry for LongTerm Fuel Cycles. Progress in Nuclear Energy, 58, 100-107. https://doi.org/10.1016/j.pnucene.2012.03.001 
[12] Iqbal, M., Mirza, N.M. and Mirza, S.M. (1997) Study of the Void Coefficients of Reactivity in a Typical Pool Type Research Reactor. Annals of Nuclear Energy, 24, 177-186 (1997). https://doi.org/10.1016/0306-4549(96)00007-2

[13] Venz, H. and Weidmann, U. (1996) Influence of Extended Cycles on Reactor Coolant Chemistry and Collective Dose at Nuclear Power Plant Beznau. Proceedings of International Conference on Water Chemistry of Nuclear Power Systems, 7, BNES, London, 16.

[14] Deeba, F., Mirza, A.M. and Mirza, N.M. (1999) Modeling and Simulation of Corrosion Product Activity in Pressurized Water Reactors under Power Perturbations. Annals of Nuclear Energy, 26, 561-578. https://doi.org/10.1016/S0306-4549(98)00087-5

[15] Barry, R.F. (1963) LEOPARD: A Spectrum Dependent Non-Spatial Depletion Code for IBM-7094, WCAP-3269-26. Westinghouse Electric Corporation, Pittsburgh.

[16] Thomas, J.R. and Edlund, H.C. (1980) Reactor Statics Module-Multi-Group Criticality Calculations, Winter College on Nuclear Physics \& Reactors-Course on Operational Physics of Power Reactors (ICTP): How to Use Nuclear Engineering Computer Modules (V.P.I., Bologna Version), (3-28 March). Trieste.

[17] Mirza, N.M., Rafique, M., Hyder, M.J. and Mirza, S.M. (2003) Computer Simulation of Corrosion Product Activity in Primary Coolants of a Typical PWR under Flow Rate Transients and Linearly Accelerating Corrosion. Annals of Nuclear Energy, 30, 831-851. https://doi.org/10.1016/S0306-4549(02)00142-1

\section{Scientific Research Publishing}

Submit or recommend next manuscript to SCIRP and we will provide best service for you:

Accepting pre-submission inquiries through Email, Facebook, LinkedIn, Twitter, etc. A wide selection of journals (inclusive of 9 subjects, more than 200 journals)

Providing 24-hour high-quality service

User-friendly online submission system

Fair and swift peer-review system

Efficient typesetting and proofreading procedure

Display of the result of downloads and visits, as well as the number of cited articles

Maximum dissemination of your research work

Submit your manuscript at: http://papersubmission.scirp.org/

Or contactwjnst@scirp.org 